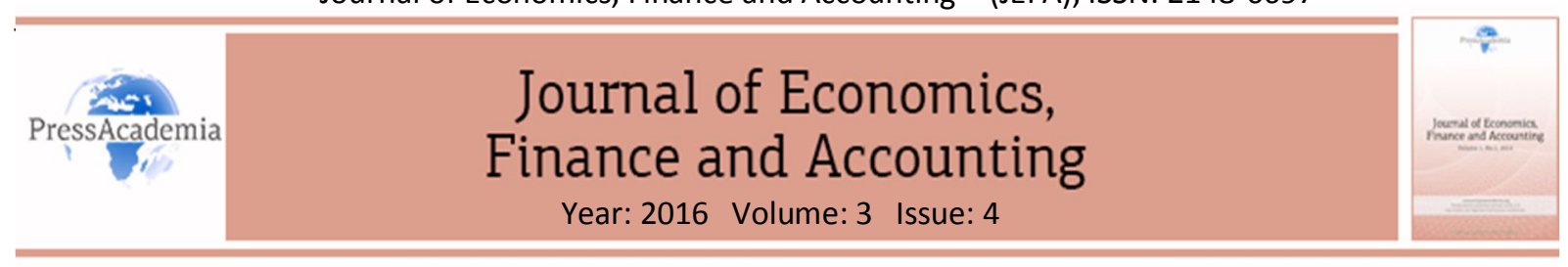

\title{
DETERMINATIONS OF SOVERIGN RATINGS: AN EMPIRICAL ANALYSIS ON TURKEY AND EU COUNTRIES*
}

\section{DOI: 10.17261/Pressacademia.2016.346}

\section{Aslı Afsar ${ }^{1}$, Emine Karacayir ${ }^{2}$}

${ }^{1}$ Anadolu Üniversitesi. aafsar@anadolu.edu.tr

${ }^{2}$ Karamanoğlu Mehmetbey Üniversitesi. e.klyc@hotmail.com

\begin{abstract}
Country credit rating explains the notes and opinions given by credit rating agencies about how much a country discharge its financial responsibilities. In this study, firstly Credit Rating Agency (CRA) is emphasized and lastly the determinants of country credit notes are analyzed. As country credit rating, the determinants of the notes given to Turkey and EU (17) countries by Moody's Credit Rating Agency, which is one of the International Credit Rating Agencies, have been analyzed. The determinants of the country credit rating are chosen in accordance with theory and literature; and five different determinants have been discoursed. According to the results of the analysis conducted with panel regression model in 2002-2014, it is concluded that the growth rate of economic growth affects the country credit rating positively and balance of foreign trade affects the credit score negatively.
\end{abstract}

Keywords: International Credit Rating Agency, Country Credit Rating, Panel Data.

JEL Classification: E62, R50, E60

\section{ÜLKE KREDI NOTUNUN BELIRLEYICILERI: TÜRKIYE VE AB ÜLKELERI ÜZERINE BIR UYGULAMA}

\section{ÖZET}

Ülke kredi notu, bir ülkenin finansal sorumluluklarını ne kadar yerine getirdiği hakkında kredi derecelendirme kuruluşlarının vermiş oldukları notları ve görüşleri açıklamaktadır. Bu çalışmada öncelikle Kredi Derecelendirme Kuruluşu (KDK) üzerinde durulmuş daha sonra bu kuruluşların vermiş oldukları ülke kredi notları açıklanmış ve son olarak ülke kredi notunun belirleyicileri incelenmiştir. Ülke kredi notu olarak Uluslararası Kredi Derecelendirme Kuruluşlarından biri olan Moody's Kredi Derecelendirme Kuruluşu tarafından Türkiye ve AB (17) ülkelerine verilen notların belirleyicileri incelenmiştir. Ülke kredi notunun belirleyicileri, teoriye ve literatür çalışmalarına uygun olarak seçilmiş beş farklı değişken üzerinde durulmuştur. 2002-2014 yıllarında panel regresyon modeliyle yapılan analiz sonuçlarına göre ekonomik büyümenin pozitif yönde, dış ticaret dengesinin ise negatif yönde ülke kredi notunu etkilediği sonucuna ulaşılmıştır.

Anahtar Kelimeler: Uluslararası Kredi Derecelendirme Notları, Ülke Kredi Notu, Panel Veri.

JEL Sınıflandırması: E62, R50, E60

\footnotetext{
*Bu çalışma 20. Finans Sempozyumu' nda bildiri olarak sunulmuş ve yapılan katkılar neticesinde revize edilmiştir.
} 


\section{GiRiş}

Bir ülkeye yapılacak olan finansal yatırımlar, o ülkenin kredi güvenilirliği ve kredi riskleri ile doğru orantılıdır. Sermaye Piyasasında Derecelendirme Faaliyeti ve Derecelendirme Kuruluşlarına İlişkin Esaslar Tebliği 5. Maddesinde kredi derecelendirmesi "işletmelerin risk durumları ve ödenebilirliklerini veya borçluluğu temsil eden sermaye piyasası araçlarının anapara, faiz ve benzeri yükümlülüklerinin vadelerinde karşılanabilirliğinin derecelendirme kuruluşları tarafından bağımsız, tarafsız ve adil olarak değerlendirilmesi ve sınıflandırılması faaliyeti" olarak tanımlanmıştır.

Birçok ülke, fon ihtiyaçlarını her zaman yerel kaynaklardan temin edememektedir. Son dönemlerde yaşanan krizlerle finans sektörünün derinleşmesi ve küreselleşmesi sonucu tasarruf sahipleri, tasarruf ihtiyacı olan kurum veya kuruluşlara finansal araçlar vasıtasıyla kredi sağlayabilmektedir. Bu nedenle Kredi Derecelendirme Kuruluşları (KDK) finansal piyasalarda önemli bir konuma sahiptir. Bu kuruluşlar vermiş oldukları notlarla yatırımcılara, yatırımlarının güvenilirliği konusunda bilgi sağlar. Kredi Derecelendirme Kuruluşları bağımsız bir şekilde kredibilite görüşünü sunan ve sundukları görüşlerle yatırımcılar, kredi talep edenler ve hükümetler tarafından çeşitli nedenlere bağı olarak kullanılan kuruluşlardır (Yazıcı, 2009:4). Bu kurumlar, yatırım kararları için kritik öneme haiz olan ülke kredi notlarını açıklayan ve güven arz eden kurumlardır.

Ülke kredi notu bir ülkede yatırım ortamının risk düzeyini göstermektedir. Fakat ülke kredi notları özel sektör borçlanmasını ve özel sektörün yabancı yatırımcılar açısından çekiciliğini de etkilemektedir.

Ülke kredi notu, bir ülkenin finansal sorumluluklarını ne ölçüde gerçekleştirdiği hakkında kredi derecelendirme kuruluşlarının açıklamış oldukları görüşleri ortaya koymaktadır. Yani kredi notu yüksek bir ülkenin uluslararası piyasada borçlanmak için ödemek zorunda olacağı faiz azalmakta, kredi notu düşük ise borçlanmanın maliyeti artmaktadır (Ovalı, 2014:54). 1989 yılından sonra Türkiye'de sermaye hareketlerinin serbestleşmesiyle birlikte yabancı sermaye girişi artmıştır. Bu durumu takiben Türkiye için kredilendirme süreci de 1991 yılında başlamıştır. 2001 bankacılık krizinden sonra Türkiye'de yaşanan birçok gelişme ile birlikte Türkiye'nin kredi notu iyileşmiştir. Küresel ekonominin hareketli olduğu dönemlerde KDK'larının önemi artmıştır. Bir ülke ya da kurum hakkında herhangi bir olumsuz görüş piyasayı oldukça olumsuz yönde etkileyebilmektedir. Bu görüş çerçevesinde yatırımcılar yatırım yapmaktan kaçınmakta ve ülkelerde likidite sorunu ortaya çıkmaktadır. Bu da krizin daha fazla derinleşmesine sebep olabilmektedir.

Krizlerin negatif etkilerini azaltmak için KDK'lar ekonomik yönden kötü olmasına karşılık, krizin derinleşmesini ve yayılmasını engellemek amacıyla yatırımların devretmesi için bazı ülkelerin kredi notunu düşürmemiş ancak bazı ülkelerin ise bu desteğe rağmen iflasını açıklaması KDK'ların eleştirilmesine ve sorgulanmasına yol açmıştır (Gür ve Öztürk, 2011: 92).

Yabancı kaynağa ihtiyaç duyan ekonomiler için kredi derecelendirme notu belirleyicileri aynı zamanda ülkenin makroekonomik durumunun da belirleyicileridir. Uzun dönemli ve hareketliliği düşük olan doğrudan yabancı sermaye yatırımları kredi notundan etkilenir fakat bunun yanında çok sayıda değişken de aynı yatırım kararlarını etkilemektedir (Kargı, 2014:355). Örneğin; ülkelerin büyüme oranlarının artması ve kalkınmasına önemli katkı sağlayacak yeni yatırımların yapılabilmesi için makroekonomik istikrarın ve politik tutarlığın sağlanması gerekmektedir. Finansal sistemin kendinden beklenen gerçek işlevleri yerine getirebilmesi için üretim girdilerinin maliyetlerinin düşürülmesi ve üretim sürecine başlama kolaylığının sağlanması büyük önem arzeder. (Kar ve Tatlısöz, 2008:5).

Uluslararası yatırım analizinde ülke kredi notunu incelerken;

-Ekonomik risk

-Devlet harcamalarında etkinlik

-Ülke kaynakları

olmak üzere üç kriter göz önünde bulundurulmalıdır (Çalışkan, 2002:56).

Kredi notları ülkelerin ekonomik durumunu birçok açıdan etkilemektedir. Özellikle ülke kredi notu ülkelerin risklilik durumunu gösterdiğinden, borçlanıcı ülkenin ödeyeceği risk primini ortaya koymaktadır. Kredi notu 
düşük ülkeler yüksek risk algısı oluşturduğundan, uluslararası piyasalardan kredi notu yüksek olan ülkelere göre yüksek faizle borçlanmaktadır (Jüttner ve McCarthy, 2000, Haspolat, 2015:1).

Bu çalışmanın amacı; ülkelerin ve kurumların hem çok önem verdiği hem de çok fazla eleştirdiği aynı zamanda rekabeti artıran, ekonomik krizlerin sinyali olarak kabul edilen ülke kredi notlarının belirleyicilerini tespit etmektir. Hangi ekonomik değişkenlerin bu belirleyiciler kapsamına alınıp alınmadığının tespit edilmesi, ülkelere kredi notlarını yükseltmede yol gösterici olmaktadır. Aynı zamanda ülkelerin ekonomi politikalarını bu doğrultuda belirlemeye yönlendirmektedir.

Çalışmada ilk olarak ülke kredi notunun belirleyicilerinin tespitine yönelik literatür taramasına yer verilmiştir. Bir sonraki bölümde teorik beklenti ve ampirik çalışmalar göz önünde bulundurularak, ülke kredi notunun hangi değişkenlerden etkilendiği sorunsalına cevap aranmıştır. Daha sonra veri seti ve yöntemin tanıtılmasının ardından elde edilen bulgular yorumlanmış, son olarak genel bir değerlendirme ile çalışma sonlandırılmıştır.

\section{LITERATÜR TARAMASI}

Kredi derecelendirme bir ülkenin finansal yükümlülüklerini zamanında ve doğru şekilde yerine getirip getirmeyeceği hakkında kredi derecelendirme kuruluşları tarafından açıklanan tarafsız, adil, şeffaf bir görüşü ifade etmektedir. Bir şirketin üretimini ülke dışına yaymak üzere ana merkezinin dışındaki ülkelerde üretim tesisi kurması veya mevcut olan tesisleri satın alması doğrudan yabancı sermaye yatıımı olarak tanımlanır (Seyidoğlu, 2013:627). Bunun yanı sıra doğrudan yabancı sermaye yatırımları teknoloji transferinde önemli bir pozisyona sahiptir (Moosa, 2002:75). Ülke kredi notu, yatııımın güvenilirliği, kâr sağlayabilmesi, likit olarak ülke dışına çıkabilmesi gibi yabancı yatıııları çekmede doğrudan etki eden önemli faktörlerden biridir. Yine ülke kredi notu açısından, doğrudan yabancı yatııımlar ele alındığında az gelişmiş ülkelerde varlıkların kamulaştııılması ve yönetimde kontrol kaybı, uluslararası şirket yöneticileri tarafından şirketlerini tehdit eden önemli unsurlar arasındadır (Kırankabeş, 2004: 69). Bu yüzden derecelendirme kuruluşlarııın vermiş oldukları ülke kredi notları önemlidir.

Gün geçtikçe derecelendirme kuruluşlarının öneminin artması veya bu kuruluşlara gelen eleştirilerden dolayı 1990'dan sonra bu kuruluşlarla ilgili çalışmalar hız kazanmıştır. Illk çalışmalardan biri olan Lee (1993) tarafından 1979-1987 döneminde Institutional Investors kuruluşunun 40 ülkeye vermiş olduğu notlar incelenmiştir. Yapılan çalışmada ülkelerin aldıkları kredilerin geri ödeme süreleri ve kredi notunu hangi faktörlerin etkilediği analiz edilmiş ve kişi başına düşen milli gelir artışı, enflasyon, faiz oranları, kişi başına milli gelir artışı varyansı, borcun ihracata oranı değişkenleri ve yüksek borçluluk kukla değişkenlerinin anlamlı olduğu sonucuna varılmıştır.

Cantor ve Packer (1996) çalışmalarında kişi başına düşen milli gelirin, GSYiH büyümesinin, enflasyonun, dış borcun, ekonomik gelişmişlik düzeyinin ülke kredi notunu etkileyen temel unsurlar olduğu sonucuna ulaşmışlardır.

Ferri ve diğerleri (1999), gelişmiş 6 ülke ve gelişmekte olan 11 ülkenin kredi notlarını 1989-1998 dönemi için Moody's notlarını göz önünde bulundurarak panel data yöntemiyle ele almışlardır. Sonuç olarak kriz dönemlerinde kredi notlarının farklılaşıı̆ını ve kriz öncesi dönemde kuruluşların kredi notlarını düşürmekte geç kaldıkları sonucunu elde etmişlerdir.

Afonso (2002), S\&P ve Moody's kuruluşlarının 1998-2001 dönemi verileriyle ve 81 ülke için en küçük kareler ve pooled veri yöntemlerini kullandığı çalışmasında ülke kredi notlarını etkileyebilecek unsurlar arasında kişi başına düşen milli gelir, büyüme, enflasyon, dış borcun ihracata oranı değişkenleriyle ekonomik kalkınmışık ve temerrüt geçmişi kukla değişkenlerinin ülke kredi notu ile ilişkisini anlamlı bulmuştur.

Mora (2005), S\&P ve Moody's kuruluşlarının öncelikle not verme yöntemlerini analiz etmiş, daha sonra verilen notları kullanarak Ferri ve diğerlerinin (1999) çalışmasını yeniden ele almıştır. 1986-2001 dönemini ve 88 ülkeyi kapsayan çalışmada Mora (2005), Ferri ve diğerleri (1999) gibi kredi derecelendirme kuruluşlarının kriz öncesinde kredi notlarını düşürmekte geciktikleri sonucuna varmıştır.

Mellios ve Blanc (2006), çalışmalarında kişi başına düşen milli gelir, hükümet gelirleri, döviz kuru değişimleri ve enflasyon oranın ülke kredi notunu etkileyen temel unsurlar olduğu sonucuna ulaşmışlardır. 
Şahinöz ve Gönenç (2011) çalışmalarında, gelişmekte olan ülkelerin öncelikle politik istikrar sağlamaları, büyümelerini artırmaları ve borçlarını azaltmalarının ülke kredi notlarının verilmesinde önemli olduğunu savunmaktadırlar.

Teker ve diğerleri (2013) çalışmalarında 1998-2010 döneminde Fitch Ratings kuruluşunun notlarını baz alarak kredi notunu belirleyen faktörleri incelemişlerdir. Birçok makroekonomik değişken kullanarak gelişmiş ve gelişmekte olan ülkelerin küresel finansal krizin ardından farklı ekonomik ve mali politikalar uyguladıklarını ve her ülkenin farklı ekonomik yapısı olduğu için farklı göstergeler ile birlikte ülkeye özgü göstergeler kullanılması gerekliliğini belirtmişlerdir.

Erkan ve Demircioğlu (2011), çalışmalarında 1995-2010 arası dönemde derecelendirme notlarını ve Türkiye'ye gelen doğrudan yabancı sermaye yatırımları arasında bir neden sonuç ilişkisinin olmadığı sonucuna ulaşmışlardır.

Kalaycı, Demir ve Gök (2010) çalışmalarında makro ekonomik değişkenleri kullanarak yaptıkları analizde, Türkiye'nin ekonomik göstergeler bakımından daha iyi bir seviyede olması gerektiği ancak sosyal ve politik faktörler yüzünden notunun düşük olduğu sonucuna ulaşmışlardır.

Emir, Uysal ve Doğru (2013), çalışmalarında (1992:1-2010:4) dönemi için DYY ile ülke riski ve makroekonomik değişkenler arasındaki ilişkiyi araştırmışlardır. Doğrudan yabancı yatırımlar GSYiH ve ülke riskinden pozitif, politik risk ve dış ticaret açığından negatif etkilendiği ve dışa açıklık oranı, reel döviz kuru değişkenleri ile anlamlı bir ilişki olduğu sonucuna ulaşmışlardır.

Balıkçıoğlu ve Yılmaz (2013) çalışmalarında 2000-2011 dönemi için üç kredi derecelendirme kuruluşunun ülke notlarını temel alarak 12 ülkenin kredi notunu incelemiş ve çalışma sonucuna göre ekonomideki yapısal unsurların kredi notu üzerinde çok etkili olmadığı sonucuna ulaşmışlardır. Bu çalışmada aynı zamanda ülke göstergelerinin notlara gecikmeli olarak yansıdığı görülmüştür.

Ovalı (2014), Türkiye'nin kredi notu ile derecelendirme kriterlerindeki performansı arasındaki ilişkiyi AB ülkeleri ile karşılaştırmalı olarak politik ve mali göstergeler açısından değerlendirmiştir. Politik istikrar, gelir düzeyi, büyüme oranı, kamu borç stoku, gelir dağılımındaki adalet, tasarrufların oranı, işsizlik oranı, finansal istikrar ve derinlik, ekonomik özgürlükler, bütçe açığı, enflasyon oranı, cari açık seviyesi değişkenlerini kullanmıştır. Türkiye'nin sadece ekonomik büyüme ve kamu borcu stoku bakımından birçok $A B$ ülkesinden başarılı olduğu sonucuna varmıştır.

\section{VERI SETI VE METODOLOJi}

Ülke Kredi notunun belirleyicilerinin tespitine yönelik yapılan çalışmanın bu bölümünde metodoloji hakkında bilgi verilecek, veri setinin elde edilme yöntemleri ve sayısal olmayan verilerin rakamlarla ifade edilmesi için yapılan transformasyon çalışması açıklandıktan sonra model kurulacaktır.

Ülke Kredi notu göstergeleri genel olarak;

- $\quad$ Politik dinamikler ve sosyal yapı

- Mali yapı

- Ekonomik yapıyı dikkate almaktadır (https://www.moodys.com/)

Tablo 1: Moody's Ülke Kredi Notunun Belirlenmesinde Kullanılan Faktörler

\begin{tabular}{|l|l|l|}
\hline Politik Skor & Kurumsal Etkinlik ve Politik Riskler & Hükümetin Etkinliği, Politikaların Etkinliği \\
\hline Ekonomik Skor & Ekonomik Yapı Büyüme Beklentisi & Milli Gelir, Büyüme, Enflasyon \\
\hline Mali Skor & Mali Performans Devlet Borcu & Borç Yükü, Borçların Sürdürülebilirliği \\
\hline Harici Skor & Likidite ve Uluslararası Yatııımlar & Likidite Riski, Dış Kırılganlık Riski, DYY \\
\hline
\end{tabular}

Kaynak: Moody's, 2013c 
Kredi notu, bir ülkenin ekonomisi ve finansal yapısı hakkında bilgi vererek yabancı yatırımcıların, yatırım yapacakları ülkeyi seçmelerinde bilgi sahibi olmalarını sağlaması açısından önemlidir. Aynı zamanda ülkenin ekonomik ve politik istikrarı hakkında bilgi verirken yatırımların ve yabancı para akışının etkisini artırmaktadır.

\section{Grafik 1: Gelişmiş Bazı AB Ülkelerinin Değişmeyen Not Durumları}

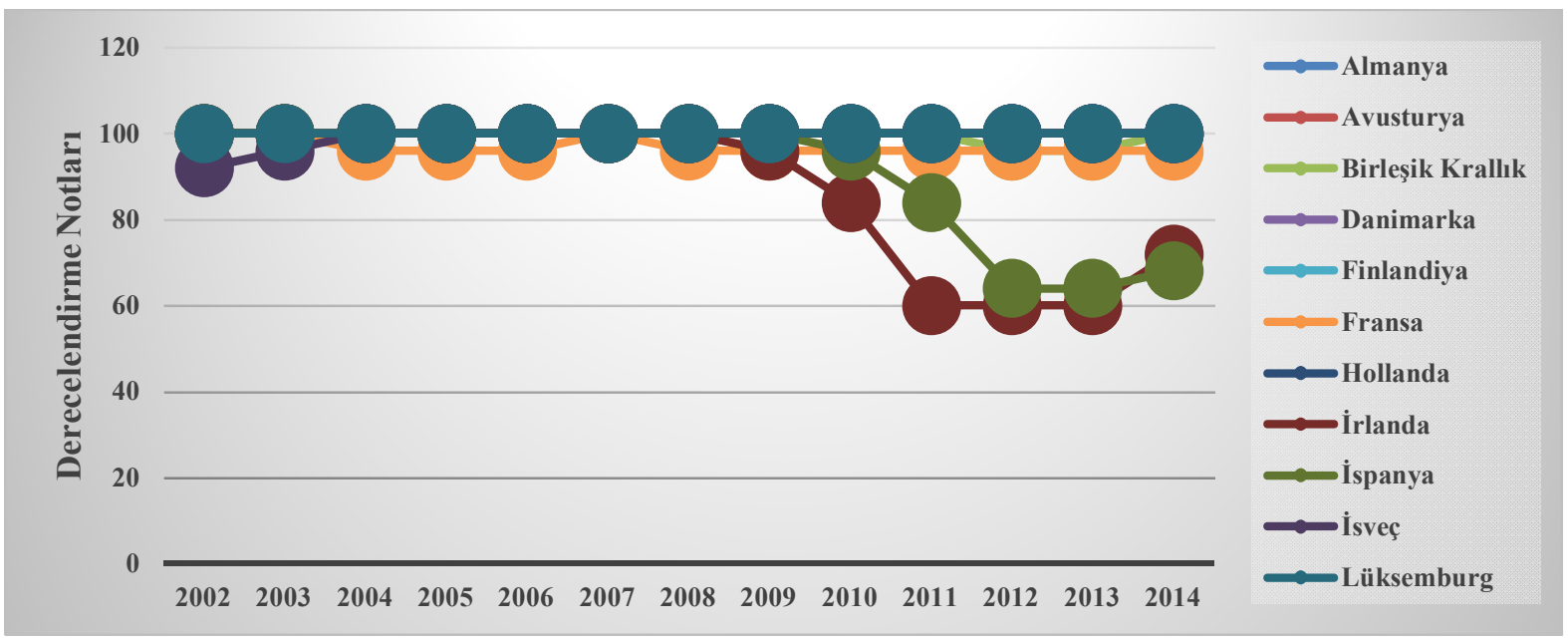

Grafikte görüldüğü gibi 11 AB üyesi ülkeden İrlanda ve İspanya haricinde 2002-2014 yılları arasındaki notlar tam veya tama çok yakın notlardır. Bu ülkelerin kriz dönemlerinde dahi notlarında bir düşme gerçekleşmemiştir. Bu durum birlik içerisinde dönem boyunca notu sabit kalmayan ülkelerin notlarının hangi makroekonomik değişkenlere göre belirlendiğini anlamaya sürüklemiş ve yapılan analizden bu ülkelerin çıkarılması fikri ortaya çıkmıştır.

Veriler incelendiğinde 2002-2014 tarihleri aralığında 29 ülke arasında özellikle gelişmiş batılı AB ülkelerin (Almanya, Avusturya, İngiltere, Danimarka, Finlandiya, Fransa, Hollanda, İrlanda, İspanya, İsveç, Lüksemburg) kredi notlarının seçilen tüm yıllarda tam veya tama yakın puanlar aldığı tespit edilmiştir. Uygulamaya dahil edilen ülkeler ise Belçika, Bulgaristan, Çek Cumhuriyeti, Estonya, Hırvatistan, İtalya, Kıbrıs, Letonya, Litvanya, Macaristan, Polonya, Portekiz, Romanya, Slovenya, Slovakya Cumhuriyeti, Türkiye, Yunanistan'dır. (Malta veri eksikliğine bağlı olarak analiz dışı tutulmuştur.

Derecelendirme kuruluşlarının notlarını temini oldukça külfetli ve zor olmasından dolayı sadece Moody's Kredi Derecelendirme Kuruluşunun vermiş olduğu ülke kredi notları ve makroekonomik değişkenlere ilişkin $A B(28)$ ülkeleriyle birlikte Türkiye'nin 2002-2014 dönemine ait yıllık veriler kullanılmıştır. Bu verilerden ülke kredi notu http://countryeconomy.com/ internet sitesinden ve eksik yıllara ilişkin veriler ise Moody's Kredi Derecelendirme Kuruluşunun internet sitesinden bulunmuştur. Diğer değişkenlere ait bilgiler aşağıdaki tabloda sunulmuş olup Dünya Bankası'nın veri sisteminden alınmıştır. Ampirik testler için Eviews 8 paket programından yararlanılmıştır.

Tablo 2: Çalışmada Kullanılan Değişkenler ve Açıklamaları

\begin{tabular}{|c|l|}
\hline Değişkenler & Açıklama \\
\hline uk & $\begin{array}{l}\text { Ülke kredi notu, Moody's tarafından açıklanan notlar transformasyon yöntemiyle } \\
\text { puantajı gerçekleştirilmiştir }\end{array}$ \\
\hline $\mathrm{g}$ & Yıllık ekonomik büyüme oranı (\%) \\
\hline $\mathrm{pg}$ & Kişi başı gelir yıllık büyüme oranı (\%) \\
\hline $\mathrm{I}$ & Enflasyon, tüketici fiyatları endeksi yıllık (\%) \\
\hline eb & $\begin{array}{l}\text { Mal ve hizmetlerin dış ticaret dengesi GSYiH payı (\%), mal ve hizmetlerin toplam } \\
\text { ihracatından toplam ithalatın çıkarılması ile ulaşııır }\end{array}$ \\
\hline $\mathrm{dyy}$ & Doğrudan yabancı yatırım girişlerinin GSYiH payı (\%) \\
\hline
\end{tabular}


Veriler incelendiğinde 29 ülke arasında özellikle gelişmiş batılı AB ülkelerinin ${ }^{*}$ kredi notlarının seçilen tüm yıllarda tam veya tama yakın puanlar aldığı tespit edilmiştir. Bu durumun seçilen serilerde yeterince değişim gösteremeyeceği bilgisi ve seçilen ülke grubundan ülke kredi notu tam veya tama çok yakın seviyede durağan olmasından dolayı söz konusu ülkelerin analiz dışı tutulmasına karar verilmiştir. Uygulamaya dahil edilen ülkelerin $^{* *}$ kredi notlarının belirleyicilerinin tespiti araştırmanın odak noktasını oluşturmaktadır. Seçilen ülkelerin ortak özelliği analiz dışında tutulan ülkelere göre ekonomik ve istikrar olarak daha geri bir seviyede yer almasıdır. Derecelendirme notları direkt olarak bir rakama karşılık gelmemesinden dolayı ekonometrik analizin yapılabilmesi için ilk önce rakamsal değerlere çevrilmesi gerekmektedir. Lineer transformasyona (LT) göre derecelendirme notları arasındaki uzaklığın eşit olması, non-lineer transformasyona göre ise eşit olmadığı, bu uzaklığın hangi nottan hareket edildiğine göre değiştiğini varsaymaktadır. Uzun dönem derecelendirme notlarında lineer transformasyonu, kurulacak modelde en düşük olan notun sıfır değeri taşımaması ve değerlendirmeye alınabilmesi için en yüksek dereceye 100 puan verilmesi ve her derece arasında 4 puan bırakılması suretiyle hesaplanmaktadır (Mukatel, 2006: 177, https://www.moodys.com/).

Tablo 3: Lineer Transformasyona (LT) ve Derecelendirme Notları

\begin{tabular}{|c|c|c|c|c|c|}
\hline $\begin{array}{c}\text { Moody' s Kredi } \\
\text { Derecelendirme } \\
\text { Kuruluşu Notu }\end{array}$ & LT & $\begin{array}{c}\text { Moody' s Kredi } \\
\text { Derecelendirme } \\
\text { Kuruluşu Notu }\end{array}$ & LT & $\begin{array}{c}\text { Moody' s Kredi } \\
\text { Derecelendirme } \\
\text { Kuruluşu Notu }\end{array}$ & LT \\
\hline Aaa & 100 & Baa1 & 72 & B2 & 44 \\
\hline Aa1 & 96 & Baa2 & 68 & B3 & 40 \\
\hline Aa2 & 92 & Baa3 & 64 & Caa1 & 36 \\
\hline Aa3 & 88 & Ba1 & 60 & Caa2 & 32 \\
\hline A1 & 84 & Ba2 & 56 & Caa3 & 28 \\
\hline A2 & 80 & Ba3 & 52 & Ca & 24 \\
\hline A3 & 76 & B1 & 48 & C & 20 \\
\hline
\end{tabular}

Tablo 4: Ülke Kredi Notunun Belirleyicilerine Yönelik Seçilen Değişkenlerin Ülke Kredi Notuna Muhtemel Etkileri

\begin{tabular}{|c|l|c|}
\hline Değişkenler & Ülke Kredi Notunu Nasıl Etkiler & $\begin{array}{c}\text { Teorik } \\
\text { Beklenti }\end{array}$ \\
\hline $\mathrm{g}$ & Ekonomik büyüme ile ülkenin borç sorumluluğunun zamanla azalması beklenir & + \\
\hline $\mathrm{pg}$ & Politik istikrar ve vergi gelirlerinde artı̧ gerçekleşir & + \\
\hline $\mathrm{I}$ & $\begin{array}{l}\text { Enflasyon oranın yükselmesi ülkelerin finansal yapısında ciddi bozulması işaret } \\
\text { etmektedir }\end{array}$ & - \\
\hline eb & $\begin{array}{l}\text { Ülkelerin mal ve hizmet dış ticaretinde ihracatın ithalatı aşması ile birlikte cari } \\
\text { fazla verilir ve borçlanma azalır. }\end{array}$ & + \\
\hline dyy & $\begin{array}{l}\text { Uzun süreli ülkeye giren doğrudan yabancı yatırımlar ülkede istikrarlı bir yapının } \\
\text { olduğunu göstermektedir. }\end{array}$ & + \\
\hline
\end{tabular}

Buna göre ekonomik büyüme, kişi başı gelirdeki büyüme oranı, dış ticaret dengesi, doğrudan yabancı yatırım girişlerinin olması durumunda politik ve ekonomik istikrara bağlı olarak ülke kredi notunun yükselmesi (ülke kredi notunun bu değişkenler ile pozitif yönlü ilişkisi), enflasyon oranındaki yükselmenin ise ülkenin mali yönden zayıflayarak ülke kredi notunu düşürücü yönde etkilemesi beklenmektedir.

\section{BULGULAR VE TARTIŞMA}

Çalışmada, ülke kredi notunu belirleyici makroekonomik değişkenlerin etkisini ölçmek amacıyla kesit ve zaman boyutunu içeren panel veri yönteminden yararlanılmıştır. Panel veri setinin heterojenliği engellemesi, çoklu

\footnotetext{
*Almanya, Avusturya, İngiltere, Danimarka, Finlandiya, Fransa, Hollanda, İrlanda, İspanya, İsveç, Lüksemburg

*** Belçika, Bulgaristan, Çek Cumhuriyeti, Estonya, Hırvatistan, İtalya, Kıbrıs, Letonya, Litvanya, Macaristan, Polonya, Portekiz, Romanya,

Slovenya, Slovakya Cumhuriyeti, Türkiye, Yunanistan (Malta veri eksikliğine bağlı olarak analiz dışı tutulmuştur)
} 
bağlantı sorununa daha az neden olması gibi birçok avantaja sahip olması, ampirik çalışmalarda sıklıkla tercih edilmesinde etkili olmaktadır. Çalışmanın zaman boyutunu 2002-2014 yılları oluştururken, 17(AB) ülkesi ise birim boyutunu oluşturmaktadır. Çalışmada seçilen makroekonomik değişkenlerin ülke kredi notu üzerindeki etkisini ölçmek için kullanılan panel veri regresyonunda literatürde hakim olan iki temel yaklaşımdan her kesit birimin kendi sabit değeri olan sabit etkiler tercih edilmiştir. (Gujarati ve Porter, 2012:603).

Çalışmanın bu bölümünde, seçilen makroekonomik değişkenlerin ve hesaplanan ülke kredi notunun durağanlık seviyesini test etmek amacıyla panel birim kök testlerine başvurulmuştur. Birim kök testi sonrasında, teorik beklenti ve literatür dikkate alınarak 4 farklı sabit etkiler panel regresyon modeli oluşturulmuştur. Model sonuçları da dikkate alınarak politik önermeler yapılmış ve ülkelerin hangi makro ekonomik değişkenlere bağlı olarak kredi notunun belirlendiği tartışılmıştır.

Zaman serileri ve panel veri analizinde, modelde kullanılacak değişkenlerin durağanlık seviyelerinin tespiti, sahte regresyon ve buna bağlı tutarsız ve etkin olmayan raporlamaların ortaya çıkmaması için önem teşkil etmektedir. Buna göre modellerde kullanılacak bütün değişkenlere panel birim kök testi yapılmış olup sonuçlar yukarıdaki tabloda raporlanmıştır. Test sonuçlarına göre modelde kullanılan uk, dyy, g, i, pg serileri sabit ile sabit ve trendin olduğu modellerde 6 farklı birim kök testinin büyük kısmında durağan olduğu; eb serisinin ise sabit modelinde sadece Hadri, sabit ve trendin olduğu modelde ise LLC ve Hadri birim kök test sonuçlarına göre durağan seviyede çıktığı görülmüştür.

Literatürde ülke kredi notunun belirleyicilerini araştıran çalışmalarda geniş bir açıklayıcı değişken setinin kullanıldığı görülmektedir. Bu çalışmada, ilgili literatür ve özellikle, Cantor ve Packer (1996), Mellios ve Blanch (2006), tarafından yapılan çalışmalarda kullanılan değişkenler dikkate alınarak dört farklı model oluşturulmuş olup bu modellerin fonksiyonel gösterimi aşağıdaki denklemlerde yazılmıştır.

$$
\begin{aligned}
& u k=f(g, e b, d y y)(1) \\
& u k=f(p g, e b)(2) \\
& u k=f(g, e b)(3) \\
& u k=f(g, e b, i)(4)
\end{aligned}
$$

Sabit Etkiler modellerine göre oluşturulan regresyon sonuçları tabloda gösterilmiş olup; Model 1 sonuçlarına göre ekonomik büyüme pozitif yönlü ve anlamlı şekilde ülke kredi notunu yükseltici etkide bulunurken, dış denge değişkeninin ülke kredi notuna etkisi negatif yönde ve anlamlı olarak tespit edilmiştir. Doğrudan yabancı yatırımlar ile enflasyon serilerinin ise ülke kredi notuna etkisi anlamlı bulunmamıştır. Model 2 sonuçlarına göre ise kişi başı gelirdeki büyüme oranı pozitif yönlü ve anlamsız şekilde ülke kredi notunu etkilemekte iken dış denge değişkeni negatif yönde anlamlı olarak ülke kredi notunu etkilemektedir. Model 3 sonuçlarına göre ise ekonomik büyümenin Model 1 de olduğu gibi pozitif yönlü ve anlamlı şekilde ülke kredi notunu yükseltici etkide bulunduğu, dış dengenin ise negatif yönde anlamlı olduğu tespit edilmiştir.

Model 4 sonuçlarına göre ise Model 1 ve Model 3'te olduğu gibi ekonomik büyümenin pozitif yönlü ve anlamlı şekilde ülke kredi notuna yükseltici etkide bulunduğu ve diğer 3 modelde olduğu gibi dış denge değişkenin ülke kredi notuna etkisinin negatif yönde ve anlamlı olduğu tespit edilmiştir. Ayrıca Model 4'te enflasyon değişkenin de ülke kredi notuna etkisinin anlamsız olduğu tespit edilmiştir. Bütün modeller bir arada değerlendirildiğinde seçilen ülkeler için kurulan regresyon denklemlerinde ekonomik büyüme, ülke kredi notunu arttırıcı yönde anlamlı, dış denge değişkenin ise ülke kredi notunu azaltıcı ve anlamlı olduğu ayrıca enflasyon ve doğrudan yabancı yatırımların ülke kredi notuna etkisinin bulunamadığı tespit edilmiştir.

Bulunan sonuçlar teorik beklentiler ile birlikte değerlendirildiğinde ekonomik büyümenin ülkelerin kredi notunu yükseltmede temel rol oynadığı ve beklentilere uygun şekilde önemli bir değişken olduğu yorumlanabilir. Beklentiler ile uyumlu çıkmayan dış denge değişkenindeki artışın ülke kredi notunu olumsuz etkilemesi ise seçilen ülke grubunun yapısal ekonomik problemini yansıtmasından kaynaklanmaktadır. Seçilen ülkeler genel olarak değerlendirildiğinde gerçekleşen ekonomik büyümelerin cari açıklarındaki artışa bağlandığı, ekonomik büyüme dönemlerinde ithalatın ihracata göre çok daha fazla artarak ülke kredi notunu yükselttikleri çıkarımı yapılabilir. Aynı şekilde bu ülkelerin genel olarak ekonomik küçülme yaşadığı yıllarda ithalatlarında yaşanan azalma ile birlikte cari açıklarında meydana gelen azalma sonucu ülke kredi notunun da azaldığı söylenebilir. 


\begin{tabular}{|c|c|c|c|c|c|c|c|c|c|c|c|c|}
\hline \multicolumn{13}{|c|}{ Sabit } \\
\hline \multirow{2}{*}{$1(0)$} & \multicolumn{2}{|c|}{ uk } & \multicolumn{2}{|c|}{ dyy } & \multicolumn{2}{|c|}{ Eb } & \multicolumn{2}{|c|}{ g } & \multicolumn{2}{|c|}{$\mathbf{i}$} & \multicolumn{2}{|c|}{ pg } \\
\hline & Stat. & $p$-value & Stat. & p-value & Stat. & $p$-value & Stat. & $p$-value & Stat. & p-value & Stat. & p-value \\
\hline LLC & 0.47085 & 0.681 & -7.0554 & $0.000^{* * *}$ & 0.58792 & 0.721 & -7.02734 & $0.000^{* * *}$ & -7.89487 & $0.000 * * *$ & -7.33691 & $0.000^{* * *}$ \\
\hline IPS & $\begin{array}{l}-6.7379 \\
\end{array}$ & $0.000 * * *$ & -5.0692 & $0.000^{* * *}$ & 2.63049 & 0.995 & -3.20554 & $0.000^{* * *}$ & -5.22694 & $0.000 * * *$ & -3.33625 & $0.000^{* * *}$ \\
\hline MW & 105.069 & $0.000 * * *$ & 86.8712 & $0.000^{* * *}$ & 15.7229 & 0.996 & 59.1674 & $0.004^{* * *}$ & 83.8276 & $0.000 * * *$ & 59.9852 & $0.003^{* * *}$ \\
\hline Choi & -4.4278 & $0.000^{* * *}$ & -5.2786 & $0.000^{* * *}$ & 2.86987 & 0.997 & -3.49395 & $0.000^{* * *}$ & -4.50105 & $0.000 * * *$ & -3.66097 & $0.000^{* * *}$ \\
\hline Hadri & 6.7066 & $0.000 * * *$ & -0.2336 & 0.592 & 5.82124 & $0.000 * * *$ & 3.58584 & $0.000^{* * *}$ & 6.45383 & $0.000 * * *$ & 3.56164 & $0.000^{* * *}$ \\
\hline \multicolumn{13}{|l|}{ I(1) } \\
\hline LLC & -1.2928 & $0.098^{*}$ & -14.562 & $0.000^{* * *}$ & -8.6376 & $0.000^{* * *}$ & -13.2076 & $0.000^{* * *}$ & -9.19516 & $0.000^{* * *}$ & -13.4267 & $0.000^{* * *}$ \\
\hline IPS & -5.7617 & $0.000^{* * *}$ & -8.9823 & $0.000^{* * *}$ & -5.1172 & $0.000^{* * *}$ & -8.52117 & $0.000^{* * *}$ & -7.92508 & $0.000^{* * *}$ & -8.60685 & $0.000^{* * *}$ \\
\hline MW & 104.573 & $0.000^{* * *}$ & 140.644 & $0.000^{* * *}$ & 88.7829 & $0.000^{* * *}$ & 131.47 & $0.000^{* * *}$ & 129.526 & $0.000^{* * *}$ & 132.598 & $0.000^{* * *}$ \\
\hline Choi & -5.0566 & $0.000^{* * *}$ & -7.841 & $0.000^{* * *}$ & -5.2725 & $0.000^{* * *}$ & -8.21555 & $0.000^{* * *}$ & -8.12859 & $0.000^{* * *}$ & -8.28817 & $0.000^{* * *}$ \\
\hline Hadri & 1.96864 & $0.0245^{* *}$ & 4.6572 & $0.000^{* * *}$ & 1.26859 & 0.1023 & 4.84003 & $0.000^{* * *}$ & 6.74714 & $0.000 * * *$ & 5.78399 & $0.000^{* * *}$ \\
\hline \multicolumn{13}{|c|}{ Sabit ve Trend } \\
\hline \multirow{2}{*}{ I(0) } & \multicolumn{2}{|c|}{ uk } & \multicolumn{2}{|c|}{ dyy } & \multicolumn{2}{|c|}{ Eb } & \multicolumn{2}{|c|}{ g } & & \multicolumn{2}{|c|}{ pg } \\
\hline & Stat. & $p$-value & Stat. & $p$-value & Stat. & p-value & Stat. & $p$-value & Stat. & p-value & Stat. & $p$-value \\
\hline LLC & -1.1571 & 0.123 & -4.7865 & $0.000^{* * *}$ & -2.7988 & $0.002 * * *$ & -7.19743 & $0.000^{* * *}$ & -6.99213 & $0.000 * * *$ & -6.85014 & $0.000 * * *$ \\
\hline Breitung & 3.18072 & 0.999 & -2.3789 & $0.008^{* * *}$ & 4.03551 & 1.000 & -3.90441 & $0.000^{* * *}$ & 0.51205 & 0.695 & -3.65697 & $0.000^{* * *}$ \\
\hline IPS & -2.9652 & $0.001^{* * *}$ & -2.5821 & $0.000^{* * *}$ & 0.10384 & 0.541 & -2.29997 & $0.010^{* * *}$ & -2.26395 & $0.011^{* *}$ & -1.92553 & $0.027^{* *}$ \\
\hline MW & 87.4926 & $0.000 * * *$ & 65.0489 & $0.001^{* * *}$ & 32.4261 & 0.5448 & 53.8083 & $0.016^{* *}$ & 60.0684 & $0.003^{* * *}$ & 51.3777 & $0.028^{* *}$ \\
\hline Choi & -2.3281 & $0.01^{* * *}$ & -3.6862 & $0.000^{* * *}$ & 0.247 & 0.5975 & -3.15061 & $0.000^{* * *}$ & -2.53442 & $0.005^{* * *}$ & -2.96318 & $0.001^{* *}$ \\
\hline Hadri & 6.7964 & $0.000^{* * *}$ & 4.90046 & $0.000^{* * *}$ & 6.14223 & $0.000^{* * *}$ & 5.20539 & $0.000^{* * *}$ & 8.51926 & $0.000 * * *$ & 5.64638 & $0.000^{* * *}$ \\
\hline \multicolumn{13}{|l|}{$I(1)$} \\
\hline LLC & -3.8187 & $0.000 * * *$ & -11.086 & $0.000 * * *$ & -7.2201 & $0.000^{* * *}$ & -10.2572 & $0.000^{* * *}$ & -3.04566 & $0.001^{* * *}$ & -10.7993 & $0.000^{* * *}$ \\
\hline Breitung & 4.17011 & 1.000 & -1.8436 & $0.032^{* *}$ & -2.1685 & $0.015^{* *}$ & -7.27803 & $0.000^{* * *}$ & -0.60875 & 0.271 & -6.77725 & $0.000 * * *$ \\
\hline IPS & -4.0192 & $0.0000^{* * *}$ & -4.7056 & $0.000^{* * *}$ & -2.4531 & $0.007^{* * *}$ & -4.03084 & $0.000^{* * *}$ & -2.70823 & $0.003^{* * *}$ & -4.20362 & $0.000^{* * *}$ \\
\hline MW & 98.2201 & $0.000 * * *$ & 101.709 & $0.000^{* * *}$ & 64.0477 & $0.001 * * *$ & 79.8685 & $0.000^{* * *}$ & 81.9512 & $0.000 * * *$ & 80.3863 & $0.000^{* * *}$ \\
\hline Choi & -5.1028 & $0.000 * * *$ & -5.3874 & $0.000 * * *$ & -3.7553 & $0.000 * * *$ & -5.14285 & $0.000^{* * *}$ & -4.81189 & $0.000^{* * *}$ & -5.17525 & $0.000^{* * *}$ \\
\hline Hadri & 9.18275 & $0.000 * * *$ & 19.7528 & $0.000^{* * *}$ & 4.98608 & $0.000 * * *$ & 27.3887 & $0.000^{* * *}$ & 16.8541 & $0.000 * * *$ & 29.6824 & $0.000^{* * *}$ \\
\hline
\end{tabular}




\begin{tabular}{|c|c|c|c|c|c|c|c|c|c|}
\hline \multicolumn{10}{|c|}{ Sabit Etkiler Modeli Panel Regresyon Tahmin Sonuçları } \\
\hline \multicolumn{5}{|c|}{ Model 1} & \multicolumn{5}{|c|}{ Model 3} \\
\hline Değişkenler & Katsayı & $\begin{array}{c}\text { Standart } \\
\text { Hata }\end{array}$ & t-istatistiği & p-değeri & Değişkenler & Katsayı & $\begin{array}{c}\text { Standart } \\
\text { Hata }\end{array}$ & $\begin{array}{c}\mathrm{t}- \\
\text { istatistiği }\end{array}$ & p-değeri \\
\hline G & 0.3222 & 0.1883 & 1.7114 & $0.0886^{*}$ & G & 0.313776 & 0.188553 & 1.664127 & $0.0976^{*}$ \\
\hline EB & -1.0939 & 0.1976 & -5.5354 & $0.0000 * * *$ & EB & -1.03217 & 0.19260 & -5.35915 & $0.0000^{* * *}$ \\
\hline DYY & -0.1554 & 0.1155 & -1.3449 & 0.1802 & C & 71.23368 & 0.865441 & 82.30912 & $0.0000^{* * *}$ \\
\hline C & 71.8278 & 0.9702 & 74.0378 & $0.0000 * * *$ & \multirow{2}{*}{\multicolumn{5}{|c|}{ R-squared $=0.495$, Adjusted R-squared $=0.447$, F-statistic $=10.392$}} \\
\hline \multicolumn{5}{|c|}{ R-squared $=0.5622$, Adjusted R-squared:0.529, Fstatistic:13.589 } & & & & & \\
\hline \multicolumn{5}{|c|}{ Model 2} & \multicolumn{5}{|c|}{ Model 4} \\
\hline Değişkenler & Katsayı & $\begin{array}{c}\text { Standart } \\
\text { Hata }\end{array}$ & t-istatistiği & p-değeri & Değişkenler & Katsayı & $\begin{array}{c}\text { Standart } \\
\text { Hata }\end{array}$ & $\begin{array}{c}\mathrm{t}- \\
\text { istatistiği }\end{array}$ & p-değeri \\
\hline PG & 0.192469 & 0.187237 & 1.027942 & 0.3052 & $G$ & 0.320382 & 0.188524 & 1.699421 & $0.0908^{*}$ \\
\hline EB & -1.09450 & 0.19159 & -5.71265 & $0.0000^{* * *}$ & EB & -1.07745 & 0.196662 & -5.478733 & $0.0000 * * *$ \\
\hline c & 71.33325 & 0.872276 & 81.77829 & $0.0000^{* * *}$ & 1 & -0.22178 & 0.197643 & -1.122126 & 0.2631 \\
\hline \multirow{2}{*}{\multicolumn{5}{|c|}{ R-squared $=0.482$, Adjusted R-squared $=0.433$, F-statistic $=9.871$}} & $\mathrm{C}$ & 71.93426 & 1.066689 & 67.43697 & $0.0000^{* * *}$ \\
\hline & & & & & \multicolumn{5}{|c|}{ R-squared $=0.561$, Adjusted R-squared $=0.519$, F-statistic $=13.524$} \\
\hline \multicolumn{10}{|c|}{ Prob. $<0.01$ ise ${ }^{* * *}, 0.01 \leq$ Prob. $<0.05$ ise $* *, 0.05 \leq$ prob. $\leq 0.10$ ise * } \\
\hline
\end{tabular}

\section{SONUÇ}

Moody's Kredi Derecelendirme Kuruluşu tarafından açıklanan ülke kredi notlarının Türkiye ve AB (17) ülkeleri açısından analiz edildiği çalışmada elde edilen sonuçlar şu şekilde özetlenebilir. İlk olarak çalışmanın ampirik kısmında ülke kredi notunun belirleyicileri literatüre ve teoriye uygun değişkenler arasından tercih edilmiştir. Sabit etkiler panel regresyon model sonuçları göstermiştir ki seçilen ülkeler için belirlenen yıl aralığında doğrudan yabancı yatııımların ve enflasyon oranının ülke kredi notuna etkisi anlamsızdır. Ekonomik büyüme pozitif ve anlamlı, dış ticaret dengesi negatif ve anlamlı olarak ülke kredi notunu etkilemektedir. Ampirik bulgulardan çıkarılabilecek temel sonuç Kredi Derecelendirme Kuruluşlarının ülke kredi notlarının belirlenmesinde bu ülkelerde ekonomik büyüme önemli bir kriterdir.

Ekonomik büyüme oranı teorik beklentilere uygun şekilde ülke kredi notunun yükselmesinde etkili olmaktadır. Teorik beklentilere uygun olmayan dış ticaret dengesinin ülke kredi notunu olumsuz etkilediği bulgusu ise seçilen ülkelerde cari açığın yapısal bir sorun haline gelmesiyle açıklanabilir. Çünkü bu ülkelerin çoğu cari açık vererek ekonomik büyüme gerçekleştirmekte ve ülke kredi notunu yükseltmekte iken, cari açığın azaldığı ekonomik küçülme dönemlerinde ise ülke kredi notu düşmektedir.

Özetle; Kredi Derecelendirme Kuruluşları politik ve ekonomik yönden istikrarı sağlamış gelişmiş AB ülkelerine makroekonomik verilerden bağımsız olarak yüksek notlar verirken bu ülkelere göre daha az gelişmiş ve yapısal sorunlar yaşayan ülkelere daha düşük notlar vermektedir. Bu ülkelerin önünde iki seçenek vardır. Illk alternatif yüksek not pahasına yapısal kronikleşen ekonomik sorunlarıyla birlikte ekonomik büyümelerini devam ettirmek veya uzun dönemde not kaygısını ikinci plana atarak kronikleşen yapısal sorunların çözümüne odaklanmaktır. İkinci alternatifin ülkeler için gerçekleştirilmesi zor olmasına rağmen; yüksek notlara sahip olunmasını sağlayacaktır. 


\section{REFERENCES}

Alessandri, T., Cerrato, D. \& Depperu, D. 2014, "Organizational slack, experience, and acquisition behavior across varying economic environments", Management Decision, vol. 56, no. 5, pp. 967-982.

Afonso, A. 2002, "Understanding the Determinants of Government Debt Ratings: Evidence for the Two Leading Agencies", Department of Economics and Research Center on the Portuguese Economy (CISEP), Universities Tecnica de Lisboa, Lisbon. Working Paper No. 02.

Balıkçıoğlu, E., \& Yılmaz, H. H. 2013, "Ülkelerin Finansal Açıdan Kredi Notlarını Etkileyen Faktörler ve Kredi Derecelendirme Kuruluşlarının Bu Faktörler Çerçevesinde Değerlendirilmesi." Maliye Dergisi, Sayı: 165, pp. 163-188.

Cantor, R. \& Packer, F. 1994, "The Credit Rating Industry" Federal Reserve Bank Of New York Quarterly Review. Summer-Fall. Vol. 19, pp.3754.

Çalışkan, Ö. V. 2002, “Kredi Derecelendirme Kuruluşları Ve Risk Değerleme Kriterleri” GÜ. iiBF Dergisi, Pp. 53-66.

Emir, M., Uysal, M. \& Doğru, B. 2013, "Ülkenin Risklilik Durumu ile Ülkeye Gelen Doğrudan Yabancı Yatırım Arasındaki ilişki: Türkiye Örneği." Atatürk Üniversitesi iktisadi Ve Idari Bilimler Dergisi, Cilt 27, Sayı 2, pp. 79-92.

Erkan, M. \& Demircioğlu, M. Y. 2011, "Türkiye'ye Verilen Derecelendirme Notlarının Doğrudan Yabancı Yatırım Girişine Etkisinin Yıllar İtibariyle İncelenmesi" İnönü Üniversitesi, Hukuk Fakültesi Dergisi, 2(1), pp. 209-239.

Ferrı, G., LuI, L. G., \& Stıglıtz, J. E. 1999, “Are Credit Ratings Pro-cyclical? Evidence from East Asian Countries.” Economic Notes 28(3), pp. 335-355.

Gür, T. H. \& Öztürk, H. 2011, “Ülke Riski, Derecelendirme Kuruluşları, Aksaklıklar ve Yeni Düzenlemeler” Sosyoekonomi Dergisi. 20112/110204, pp. 69-92

Haspolat, F. B. 2015, “Ülke Kredi Notlarının Belirleyicileri Türkiye’nin Kredi Notunun Ülke Karşılaştırmalı Analizi” Kalkınma Bakanlığı Uzmanlık Tezi Yayın No:2913, pp. 1-157.

Jüttner, J.D. \& Mccarthy, J., (2000), “Modeling A Rating Crisis”, Macquarie University, Unpublished, Sidney, Australia.

Kalaycı, Ş., Demir, Y. \& GÖK, I. Y. (2010), "Ülke Kredi Notunun Temel Makro Ekonomik Belirleyicileri: AB Ülkeleri Ve Türkiye Üzerine Bir Reyting Araştırması”, Finans Politik \& Ekonomik Yorumlar. Cilt 47, Sayı 544, pp. 15-28.

Kar, M. \& Tatlısöz, F. 2008, "Türkiye'de Doğrudan Yabansı Sermaye Hareketlerini Belirleyen Faktörlerin Ekonometrik Analizi", KMU iiBF Dergisi, Yıl:10 Sayı 14.

Kargı, B. 2014, “Uluslararası Kredi Derecelendirme Kuruluşları ve Türkiye'nin Kredi Notu Üzerine Bir İnceleme” International Journal Of Social Science. Number;24, pp.351-370.

Kırankabeş, M. C. 2004, “Ülke Riskinin Doğrudan Yabancı Yatırımlara Etkisi 1984-2003 Dönemi Türkiye Değerlendirmesi” Dumlupınar Üniversitesi, Sosyal Bilimler Enstitüsü Iktisat Anabilidalı Yayımlanmamış Yüksek Lisans Tezi, Kütahya.

Lee, S. H. 1993, “Are the Credit Ratings Assigned by Bankers Based on the Willingness of LDC Borrowers to Repay?” Journal of Development Economics No:40, pp. 349-359.

Mellios, C. \& Paget-Blanc, E.; (2006), "Which Factors Determine Sovereign Credit Ratings?”, The European Journal of Finance, 12(4), 361377.

Moosa, I. A. 2002, Foreign Direct Investment: Theory, Evidence and Practice, New York, Palgrave Macmillan.

Moody's History: A Century of Market Leadership, 24 Ekim 2013 https://www.moodys.com/Pages/atc001.aspx

Mora, N. 2005, "Sovereign Credit Ratings: Guilty Beyond Reasonable Doubt?" Lecture And Working Paper, Series No. 1, American University of Beirut Institute of Financial Economics, Beirut, pp.1-36.

Mukatel A. L. 2006, "Ülke Derecelendirme Notlarının Borsa Endekslerine Etkisi: IMKB 100 Endeksi Üzerine Bir Model Denemesi” Marmara Üniversitesi Bankacılık Ve Sigortacılık Enstitüsü Sermaye Piyasası Ve Borsa Anabilimdalı.

Ovalı, S. 2014. "Ülke Kredi Notu Değerlendirme Kriterleri Açısından Türkiye: Ab ile Karşılaştırmalı Analiz" Uluslararası Yönetim iktisat ve işletme Dergisi, Cilt 10, Sayı 23, pp. 53-81.

Şahinöz, S. \& Gönenç, R. 2011, “Determinants of Credit Ratings, Sovereign Bond Spreads and Real Interest Rates In Emerging Markets”, iktisat Işletme ve Finans, 26 (305), pp.9-35.

Teker D., Pala, A. \& Kent O. 2013, "Determination of Sovereign Rating: Factor Based Ordered Probit Models for Panel Data Analysis Modelling Framework", International Journal of Economics and Financial, Issues Vol. 3, No. 1, pp. $122-132$.

Yazıcı, M. 2009, "Kredi Derecelendirme Kuruluşlarının Önemi venetimi” http://www.finanskulup.org.tr/assets/maliyefinans/82/Mehmet Yazici Kredi Derecelendirme Kuruluslarinin Onemi ve Denetimi.pdf. (10.02.2016).

https://www.moodys.com/.

http://www.spk.gov.tr/apps/teblig/index.aspx?lang. 